\title{
Calculating Methods for Quantifying Environmental Flows in Estuaries: A Case Study of Haihe River Basin, China
}

\author{
Z. F. Yang ${ }^{1,2}$, T. $\operatorname{Sun}^{1 *}$ and X. S. Qin ${ }^{3}$ \\ ${ }^{1}$ State Key Laboratory of Water Environment Simulation, Beijing Normal University, Beijing 100875, China \\ ${ }^{2}$ Environmental School, Beijing Normal University, Beijing 100875, China \\ ${ }^{3}$ Environmental Systems Engineering Program, Faculty of Engineering, University of Regina, Regina S4S 0A2, Canada
}

\begin{abstract}
This paper developed a new method for quantifying environmental flows in estuaries. Three types of water requirements were included in calculations: the water cycle, the biological cycle, and the habitat. Three estuaries of the Haihe River Basin in China were presented as case studies for verifying the applicability and practicability of the proposed method. The results indicated that the minimum annual environmental flow requirements for the Haihe, Luanhe and Zhangweixin Estuaries were $5.97 \times 10^{8}, 6.80 \times 10^{8}$ and $4.96 \times 10^{8} \mathrm{~m}^{3}$ respectively. For the Luanhe Estuary, the annual freshwater inflow was sufficient for achieving the ecological objectives. The estuarine ecosystems in the Haihe and zhangweixin estuaries have degenerated significantly over the past decades and could not be rehabilitated naturally. The spatial variations in the environmental flows were related to the differences between the local climate conditions and the fluvial flow regimes of the estuaries. The temporal variations were influenced by the climatic conditions. Sediment transport was affected directly by reductions of river discharge, and so was the balance of salinity.
\end{abstract}

Keywords: Calculating methods, environmental flows, estuarine ecosystem, Haihe River Basin

\section{Introduction}

Studies of environmental flows in aquatic systems have aroused much interest among researchers over the past decades (Jowett, 1997; Gipple and Stewardson, 1998; King and Louw, 1998; Cui et al., 2002; Tharme, 2003; Yang et al., 2003; Benetti et al., 2004). However, most of their works focused on rivers and wetlands. Investigations on estuaries are relatively scarce due to difficulties in addressing complex responses of estuarine ecosystems to freshwater inflows and collecting required ecological data. The environmental flow for estuary is normally defined as the level of freshwater inflow that is needed by the estuarine ecosystem to achieve satisfactory ecological objectives. Quantification of this value is generally hard since the traditional methodology for studying the fluvial systems cannot be directly employed. Therefore, development of new approaches for calculating environmental flows in estuaries is desired.

Previously, a number of prelimilary studies in this field were reported. For examples, the Southwest Florida Water Management District (SWFWMD) developed a variety of management approaches in order to protect the environmental flows for estuaries based on different ecological objectives; " $10 \%$ presumption" was established given that water utilization will not cause unacceptable environmental impacts if it

\footnotetext{
* Corresponding author: suntao@bnu.edu.cn
}

does not reduce the rate of daily flow by more than $10 \%$ (Flannery et al., 2002). A resource-based inflow standard was established in the Loxahatchee and the Caloosahatchie Estuaries in Florida through a valued ecosystem component (VEC) method (Doering et al., 2002). In case studies, three kinds of seagrass were identified as key species; and the method that was based on the relationship between inflow and the catch of fish was proposed as a management tool for protecting the estuarine ecosystems in Texas (Matsumoto et al., 1994). Adams and Bate (1994) investigated the environmental flows of estuaries in river basins of South African, where hydrological, geomorphological and ecological variables were taken into account. More recently, a number of comprehensive studies on Australian estuaries such as Port Phillip Bay and Huon River were reported, where the methods of quantifing appropriate levels of environmental flows were introduced (Peirson et al., 2002).

However, the previous studies only focused on limited functions of estuarine ecosystems, leading to over-simplified descriptions on characteristics of the environmental flows and possible errors in predicting the flow levels. To fill this gap, this paper aims to develop a new method for quantifying the environmental flows in estuaries in consideration of a boarder range of functions. Scarcity of ecological data in estuaries will also be dealt with. Three estuaries of Haihe River Basin in China will be investigated for verifying the applicability and practicability of the proposed method. 


\section{Characteristics of Environmental Flows in Estuaries}

The characteristics of environmental flows in an estuary include water quantity, water quality, and temporal/spatial variations.

\subsection{Water Quantity}

The basic requirements for environmental flows are to ensure the structure integrity and the stability for the estuarine ecosystem, which is directly related to water consumptions in the water cycle (precipitation, evaporation and infiltration) and the biological cycle (different trophic levels). For the freshwater wetlands in the estuarine ecosystem, water surface areas, water depths and flow velcocities of the wetlands in the estuaries may also be important issues to be accounted for.

\subsection{Water Quality}

Water body in a river contains many kinds of suspended particles, such as sediments and nutrients. Environmental flows for protecting water quality normally refer to the levels of freshwater discharge for keeping the balance of sediment and maintaining a well mixture of nutrient and freshwater in estuaries. The requirements of water quantity and quality for the environmental flows in estuaries are to ensure that the physical, chemical and biological balances in the ecosystem are well maintained. Excessive or less flow levels will generally not be acceptable. Thus, it is necessary to determine the upper and lower bounds of the flow levels in order to ensure the ecological objectives.

It should be noted that the problem of high-level nutrient loads, which used to be identified as pollutantion levels, can not be solved through water dilution. Such an approach is only acceptable when water quality standards are met. This can be realized through appropriate sewage treatment or other mitigation measures.

\subsection{Temporal Variation}

Most of species in estuaries are migrating. Seasonal and annual variations of the environmental flows are significant in estuaries. However, the natural allocation of the freshwater and the nutrients input may be easily interrutped due to excessive water utilization in river basins or inappropriate construction of tidal barrages. As a result, the requirements of different ecological objectives can not be acheived simultaneously in the estuarine ecosystems. Therefore, to ensure a healthy ecological environment, it is important that the temporal variations of the environmental flows in estuarine ecosystems be close to those occur in natural conditions.

\subsection{Spatial Variation}

Different types of estuaries vary in topography, sediment supply, climate condition and other factors. The requirements of the environmental flows also exhibit significant variations in different types of estuaries. Identification of main threats or ecological objectives for an estuary is necessary before any study on environmental flows is undertaken.

Besides the basic requirements of estuarine ecosystem, the estuaries also perform as the breeding and nesting habitats for a number of endangered or precious species because of their unique living environment. Thus, special attentions must be paid to these situations during evaluation of the environmental flows.

Based on above analysis, it is obvious that three types of water requirements should be considered in estimating the environmental flows. They consist of the water requirements for the water cycle, the biological cycle and the habitat. Environmental flows for estuarine ecosystem should fulfill the water requirements of water and biological cycles, maintain water surface area and depth for freshwater wetland, keep balance of salinity, and sustain sediment and nutrients transport for the habitat. Temporal changes of environmental flows should be analyzed specially.

\section{Calculating Methods for Quantifying the Environmental Flows in Estuaries}

\subsection{Environmental Flows for Water Cycle}

Water consumption in evaporation and infiltration should be considered in calculating the water requirements of the water cycle. The net water requirements for evaporation $\left(W_{e}\right)$ can be given by:

$W_{e}=\bar{E} A_{\text {Water }}+\alpha \bar{E} A_{\text {Plant }}-\bar{P} A_{\text {Total }}$

where $\bar{E}$ and $\bar{P}$ are the average potential evaporation and precipitation in the area, respectively; $A_{\text {Total }}$ is the total wetland area; $A_{\text {Water }}$ is the water surface area; $A_{\text {Plant }}$ is the area of vegetation covers; $\alpha$ is the reduced evaporation from vegetation covered area compared to the potential evaporation. The value of $\alpha$ is typically around $60 \%$ to $100 \%$ of the potential evaporation.

The water requirement of soil $\left(W_{s}\right)$ is assumed to be related to that of infiltration due to complicated relationship between surface water and ground water. It can be given as (Cui and Yang, 2002):

$W_{s}=\beta H A_{S}$

where $\beta$ is the field water capacity which can be set as 20,40 and $50 \%$ under different grade levels; $H$ is the soil thickness; $A_{S}$ is the soil area.

\subsection{Environmental flows for Biological Cycle}

The environmental flows for biological cycle $\left(W_{b}\right)$ are mainly estimated by the biological water content, which is calculated as follows (Yang et al., 2003): 
$W_{b}=\sum_{i=1}^{m} W_{b i}=\sum_{i=1}^{m} \gamma_{i} W_{i} A_{B}$

where $W_{b i}$ is the water requirements for the $i$ th species; $m$ is the number of species; $\gamma$ is the water content of biota; $W_{i}$ is the biomass; $A_{B}$ is the area of biologic distribution. The grade levels for water requirements in the biological cycle can be determined based on $W_{i}$ and $A_{B}$.

\subsection{Environmental Flows for Wildlife Habitat}

\subsubsection{Environmental flows for the freshwater wetland}

The function of the environmental flows for the freshwater wetland is to maintain certain levels of water surface area and water depth, as well as to achieve necessary water-body renewal. It is given by:

$W_{w}=\mu \gamma A_{w} H$

where $\mu$ is the ratio of water surface to total wetland area; $\gamma$ is the water exchange period (time ${ }^{-1}$ ). $A_{w}$ is the total wetland area; $H$ is the average water depth within the water surface area. It is generally difficult to estimate the level of $\gamma$. This is due to the fact that the required water exchange under a certain pollution load depends on water quality objectives (e.g. water transparency, algae amonts, BOD levels, nutrient levels, trace-metal and specific organic compound concentrations). When $\gamma$ is 0 , the environmental flows for the freshwater wetland will not be considered.

\subsubsection{Environmental flows for balance of salinity}

Mixture of freshwater and saltwater is a basic characteristic of estuary. Generally, environmetnal flows should be properly controlled to ensure the salinity in the estuary be maintained at a certain level. The relationship between the river discharge and the salinity level in estuary is difficult to be described due to existences of complex mixing and circulating processes, as well as changing weather conditions. With single well-mixed volume of water being assumed, the method outlined in this paper for assessing the required freshwater outflow can only be regarded as an order of magnitude approximation. However, this approach can be enhanced if additional sequential boxes are introduced.

Balance of salinity $(S)$ over time in the water body can be written as:

$\frac{d S}{d t}=\frac{\Delta Q \cdot S_{0}+\Delta V_{k 1} \cdot S_{\text {sea }}-\Delta V_{1 k} \cdot S_{\text {estuary }}}{V_{1}}$

where $\Delta Q$ is the freshwater discharge to the estuary; $S_{0}$ is the salinity in the discharged water; $S_{\text {estuary }}$ is the salinity in the estuary at a previous time step; $S_{\text {sea }}$ is the salinity in the sea outside the estuary; $V_{1}$ is the volume in the estuary (box I); $V_{k 1}$ is the volume flowing from the sea into the estuary; $V_{1 k}$ is the volume flowing from the estuary into the sea.

For a steady state condition, the change in salinity over time is zero, i.e. $d S / d t=0$. In addtion, the salinity of the freshwater discharge is assumed to be zero, i.e. $S_{0}=0$. Thus, the above equation can be simplified into:

$\Delta V_{k 1} \cdot S_{\text {sea }}=\Delta V_{1 k} \cdot S_{\text {estuary }}$

where $\Delta V_{k 1}$ and $\Delta V_{1 k}$ are the volumes of water exchanges from the sea to the estuary and from the estuary to the sea, respectively. These volumes represent the amount of water circulates between the estuary and the sea.

Assume that no net change in volume occurs during calculation. We have:

$\Delta V_{1 k}=\Delta V_{k 1}+\Delta Q$

where $\Delta Q$ is the freshwater discharge in the concerned period. Combine equations (6) and (7), we can obtain:

$\Delta V_{1 k}=\frac{\Delta Q}{\left(\frac{S_{\text {sea }}}{S_{\text {estuary }}}-1\right)}+\Delta Q$

The above equations and the calculation of the required freshwater inflow can be further simplified when the water exchange of the estuary in the calculation period is equal to the estuary volume, i.e. $\Delta V_{1 k}=V_{1}$.

An indicator $\lambda$ that is defined as the ratio of freshwater discharge to the total estuary volume is introduced to control the salinity levels in estuaries $\left(S_{\text {estuary }}\right)$ :

$\lambda=\frac{S_{\text {sea }}-S_{\text {Estuary }}}{S_{\text {sea }}}$

where the salinity in the sea $\left(S_{\text {sea }}\right)$ is assumed to be constant for the calculation period. Environmental flows for maintaining a certain level of salinity $\left(W_{f}\right)$ in the estuary can be determined as follows:

$W_{f}=\lambda \cdot V_{\text {estuary }}$

where the volume of estuary can be approximated by $V_{\text {estuary }}=1 / 3 A_{0} H ; A_{0}$ is the surface area of the estuary; $H$ is the water depth at the boundary between the estuary and the sea. The salinity in the sea $\left(S_{\text {sea }}\right)$ is assumed constant for the calculation period, which is selected as one season. The grade levels of water requirements for calculating the balance of salinity can be determined based on the seasonal objectives $\left(S_{\text {estuary }}\right)$ for the estuaries.

Generally, there are two extreme conditions: a) $\lambda=0$, e.g. 
no freshwater inflow to estuary $\left(S_{\text {estuary }}=S_{\text {sea }}\right)$; b) $\lambda=1$, e.g. estuary is totally dominated by freshwater $\left(S_{\text {estuary }}=0\right)$.

\subsubsection{Environmental flows for sediment transport}

Water requirements for sediment transport are affected by the carrying capacity of sediment and the quantity of the alluvial sediment in the estuary, which can be expressed by

$W_{t}=Q_{i} / C_{i}$

where $W_{t}$ is water requirements for sediment transport; $Q_{i}$ is the quantity of alluvial sediment in the estuary; $C_{i}$ is the sediment carrying capacity $\left(\mathrm{kg} / \mathrm{m}^{3}\right)$, which is related to the characteristic of sediment. The minimum water requirements for sediment transport normally correspond to the maximum level of sediment carrying capacity.

The nutrients loads also have considerable impacts on the esturine ecosystems. To address these factors, a much more sophisticated model is generally required. In this study, it is assumed that the environmental flows for keeping salinity balance and sustaining sediment transport also meet the basic requirement of water quality.

The environmental flows in the estuaries can be divided into the consumptive and the non-consumptive water volumes assigned to meet the ecological objectives. The water requirements for sustaining biological cycle, ensuring evaporation, keeping certain levels of water surface area and water depth of the freshwater wetland are considered as consumptive. The water requirements for maintaining balance of salinity and sediment/nutrients transport for habitat are non-consumptive. The rule of summation is generally applied for calculating consumptive water requirements; while the rule of compatability (e.g. maximum principle) is adopted for estimating nonconsumptive ones. Thus, the total environmental flows for the estuaries are:

$W_{\text {estuary }}=W_{e}+W_{s}+W_{b}+M A X\left(W_{f}, W_{t}, W_{w}\right)$

where $W_{\text {estuary }}$ are the environmental flows for the estuaries; $\operatorname{MAX}(a, b, c)$ denotes the maximum of variables $a, b$ and $c$.

\section{Application of the Calculating Methods in the Haihe River Basin}

Estuaries of the Haihe River Basin are located at the east of the Basin and west of the Bohai bay, China. Over the past decades, degradation of the estuarine ecosystem has been exacerbated due to increasing pollutant discharges and excessive water resource utilizations. In order to sustain a fast economic development and, at the same time, minimize negative influence of the reduced river discharges, proper levels of environmental flows under various ecological objectives for estuaries should be identified. In this study, three estuaries in the Haihe River Basin, i.e. the Haihe, the Luanhe and the Zhangweixin Estuaries, will be selected for calculations.

Table 1. Water Requirements for the Consumption through Evaporation, $W_{e}\left(10^{8} \mathrm{~m}^{3}\right)$

\begin{tabular}{llll}
\hline Grade levels & $\begin{array}{l}\text { Haihe } \\
\text { Estuary }\end{array}$ & $\begin{array}{l}\text { Luanhe } \\
\text { Estuary }\end{array}$ & $\begin{array}{l}\text { Zhangweixin } \\
\text { Estuary }\end{array}$ \\
\hline Water surface area $\left(\mathrm{km}^{2}\right)$ & 325.0 & 410.0 & 300.0 \\
Maximum & 6.10 & 4.90 & 3.55 \\
Medium & 4.10 & 3.50 & 3.00 \\
Minimum & 3.50 & 2.34 & 2.60 \\
\hline
\end{tabular}

Estuaries in the Haihe River Basin belong to arid and semi-arid regions. In general, evaporation exceeds precipitation in this area (Figure 1). Based on the series hydraulic data and the landuse information in different estuaries, the water requirements for evaporation in the main estuaries of the Haihe River Basin can be obtained (Table 1). Parameters for calculating the water requirements for biological cycle are listed in Table 2.

Based on the salinity objectives for the estuaries in different seasons, the parameter $\lambda$ (ratio of the volume of the freshwater discharge to the total volume of the estuary) under different grade levels can be calculated (Table 3 ). Then, the water requirements for salinity balance can be estimated through Equation (4). The results are listed in Table 4.

Table 5 shows the annual water requirements for sediment transport in different estuaries under different grade levels. In consideration of the compatibility between the water requirements for the sediment transport as well as the salinity balance, the water requirements for the runoff to the ocean

Table 2. Parameters Related to Environmental Flows for Biological Circle in the Estuary

\begin{tabular}{|c|c|c|c|c|c|c|}
\hline & & \multirow{2}{*}{$\begin{array}{c}\text { Primary production } \\
\text { Aquatic plant } \\
\mathrm{g} /\left(\mathrm{m}^{3} \cdot \mathrm{a}\right)\end{array}$} & \multicolumn{2}{|c|}{ Secondary production } & \multicolumn{2}{|c|}{ High trophic level } \\
\hline & & & $\begin{array}{c}\text { Phytoplankton } \\
\mathrm{g} /\left(\mathrm{m}^{3} \cdot \mathrm{a}\right)\end{array}$ & $\begin{array}{c}\text { Zooplankton } \\
\mathrm{g} /\left(\mathrm{m}^{2} \cdot \mathrm{a}\right)\end{array}$ & $\begin{array}{l}\text { Benthos } \\
\mathrm{g} /\left(\mathrm{m}^{2} \cdot \mathrm{a}\right)\end{array}$ & $\begin{array}{c}\text { Migrate fish } \\
\mathrm{t} /\left(\mathrm{km}^{2} \cdot \mathrm{a}\right)\end{array}$ \\
\hline \multirow[t]{3}{*}{ Biomass } & Maximum & 4.0 & $2.5 \sim 3.5$ & $2.5 \sim 3.5$ & $>25.0$ & $>25.0$ \\
\hline & Medium & 2.0 & $2.0 \sim 2.5$ & $2.0 \sim 2.5$ & $10.0 \sim 25.0$ & $10.0 \sim 25.0$ \\
\hline & Minimum & 1.0 & $1.5 \sim 2.0$ & $1.0 \sim 2.0$ & $5.0 \sim 10.0$ & $5.0 \sim 10.0$ \\
\hline Ratio of water content & & $60 \%$ & $90 \%$ & $80 \%$ & $70 \%$ & $70 \%$ \\
\hline
\end{tabular}




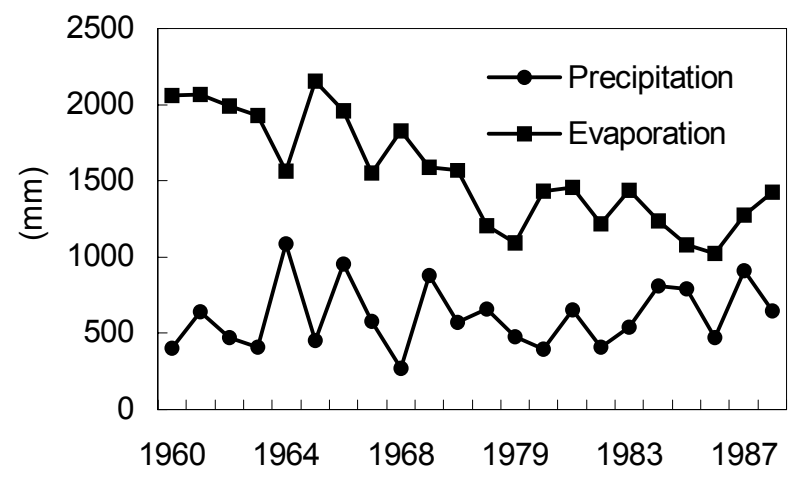

(a)

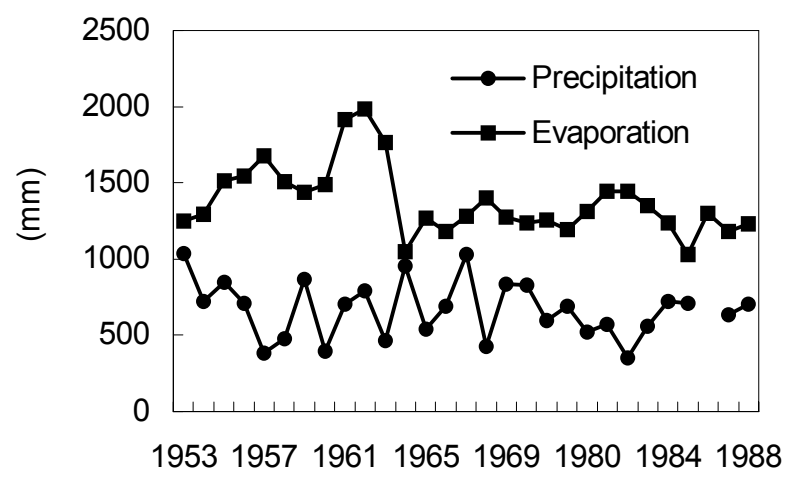

(b)

Figure 1. Annual variations of precipitation and evaporation in the estuaries: (a) Haihe Estuary, (b) Luanhe Estuary.

Table 3. Parameters Related to the Requirements of the Balance of Salinity with Different Grade Levels

\begin{tabular}{lllll}
\hline Parameters & Spring & Summer & Autumn & Winter \\
\hline Salinity in ocean & 32.0 & 32.0 & 32.0 & 32.0 \\
Salinity in near-shore zone & Between summer and winter & $24.0 \sim 27.0$ & Between summer and winter & $29.0 \sim 30.0$ \\
$\lambda \quad$ Maximum & 0.11 & 0.16 & 0.11 & 0.0625 \\
$\quad$ Medium & 0.14 & 0.20 & 0.14 & 0.078 \\
$\quad$ Minimum & 0.17 & 0.25 & 0.17 & 0.094 \\
\hline
\end{tabular}

can be determined based on Equation (12) (as shown in Figure 2). The allocation of the monthly environmental flows is assumed to be close to the natural distribution of river discharge. The natural flows in estuaries of the Haihe River Basin are illustrated in Figure 3.

Table 4. Water Requirements for the Balance of Salinity in Estuarine Habitat $\left(10^{8} \mathrm{~m}^{3}\right)$

\begin{tabular}{lllll}
\hline & & $\begin{array}{l}\text { Haihe } \\
\text { Estuary }\end{array}$ & $\begin{array}{l}\text { Luanhe } \\
\text { Estuary }\end{array}$ & $\begin{array}{l}\text { Zhangweixin } \\
\text { Estuary }\end{array}$ \\
\hline $\begin{array}{l}\text { Water depth at the } \\
\text { end of estuary }\end{array}$ & $(\mathrm{m})$ & 8 & 10 & 8 \\
Estuary area & $\left(\mathrm{km}^{2}\right)$ & 210 & 300 & 250 \\
Maximum & 0.2 & 4.48 & 8.0 & 4.26 \\
Medium & 0.15 & 3.36 & 6.0 & 3.2 \\
Minimum & 0.1 & 2.24 & 4.0 & 2.13 \\
\hline
\end{tabular}

It is indicated that the seasonal variation of the natural river discharge approximatively obeys a normal distribution. Consequently, the temporal variation of the monthly environmental flows can be calculated based on normal distributions as follows:

$W_{x}=\frac{W}{\sqrt{2 \pi} \sigma} e^{-\frac{(x-\mu)^{2}}{2 \sigma^{2}}}$ where $x$ is the month; $\mu$ denotes the month when the ratio of water requirements to the year total is maximum; the $\sigma$ (normally $2.0,1.0$, and 0.75 ) denotes the allocation of water quantity in the year.

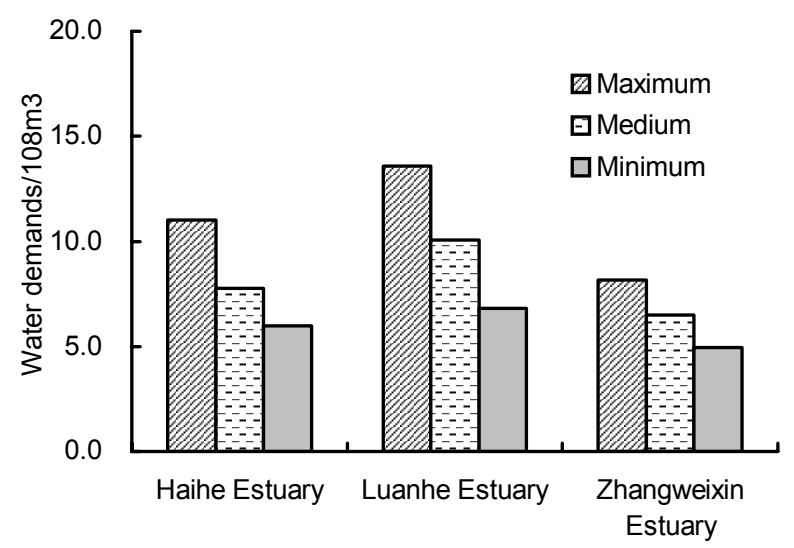

Figure 2. Annual environmental flows for the estuaries in the Haihe River Basin

\section{Analysis and Discussions}

\subsection{Environmental Flows and River Discharges}

Table 6 presents the comparison between environmental 


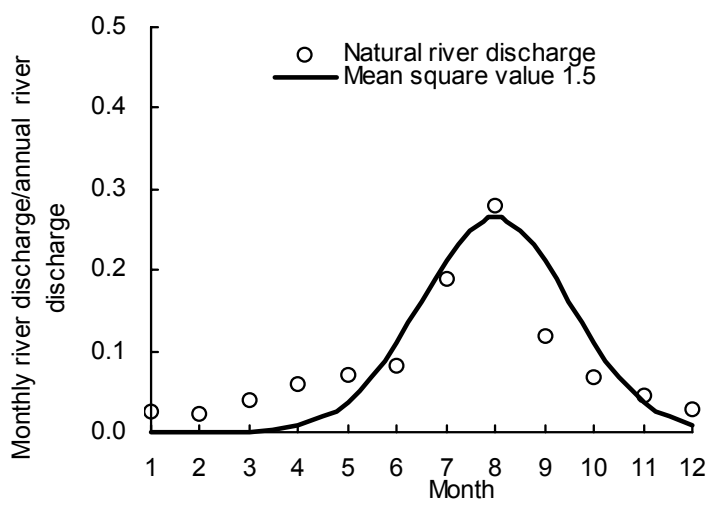

(a) Luanhe Estuary

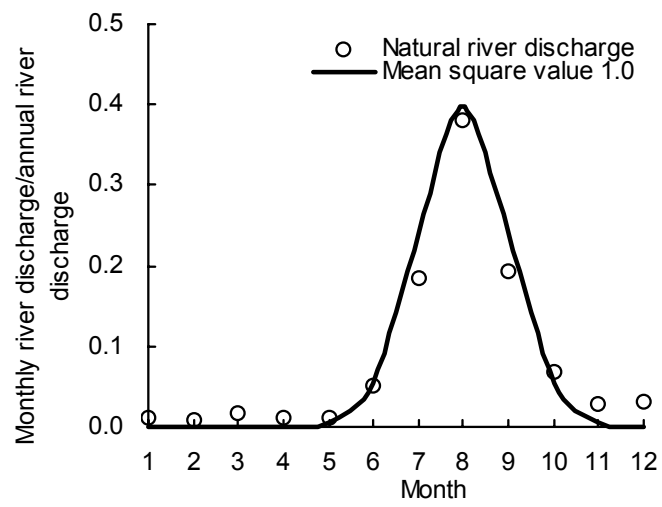

(b) Haihe Estuary

Figure 3. Distribution of the monthly natural river discharge for the estuaries and the normal distribution.

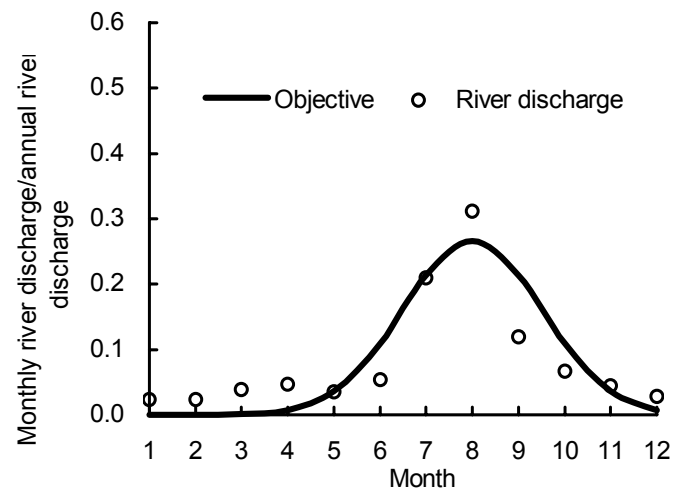

(a) $1950 \sim 1960 \mathrm{~s}$

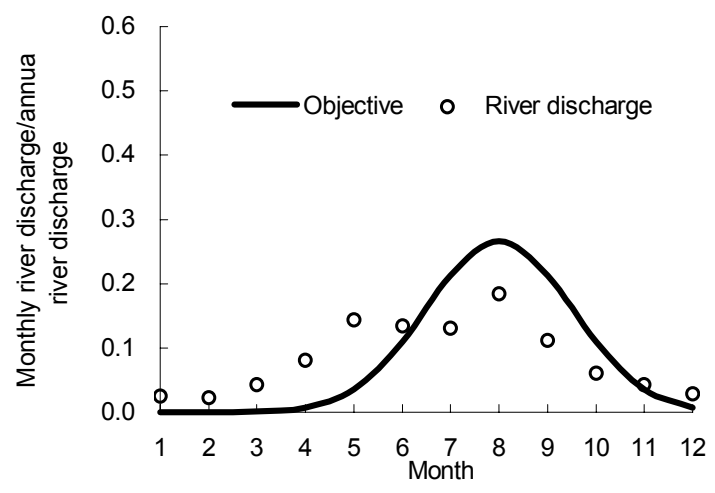

(b) $1980 \mathrm{~s}$

Figure 4. Monthly river discharges and their temporal variations in the Luanhe Estuary.

Table 5. Water Requirements for Sediment Transport and Runoff to the Ocean for the Estuaries in the Haihe River Basin $\left(10^{8} \mathrm{~m}^{3}\right)$

\begin{tabular}{|c|c|c|c|c|c|c|c|c|c|}
\hline \multirow[b]{2}{*}{ Grade Level } & \multicolumn{3}{|c|}{ Haihe Estuary } & \multicolumn{3}{|c|}{ Luanhe Estuary } & \multicolumn{3}{|c|}{ Zhangweixin Estuaary } \\
\hline & Minimum & Medium & Maximum & Minimum & Medium & Maximum & Minimum & Medium & Maximum \\
\hline$C_{i}\left(\mathrm{~kg} / \mathrm{m}^{3}\right)$ & 30.0 & 15.0 & 3.0 & 30.0 & 15.0 & 3.0 & 30.0 & 15.0 & 3.0 \\
\hline $\begin{array}{l}\text { Annual sediment } \\
\text { transport }\left(10^{7} \mathrm{~kg}\right)\end{array}$ & \multicolumn{3}{|c|}{$154.23(1958 \sim 1989)$} & \multicolumn{3}{|c|}{$317.71(1978 \sim 1990)$} & \multicolumn{3}{|c|}{$107.54(1980 \sim 1989)$} \\
\hline $\begin{array}{l}\text { Water demands for } \\
\text { sediment transport }\end{array}$ & 0.51 & 1.03 & 5.14 & 1.06 & 2.12 & 10.59 & 0.36 & 0.72 & 3.58 \\
\hline $\begin{array}{l}\text { Water demands for } \\
\text { runoff to ocean }\end{array}$ & 2.24 & 3.36 & 5.14 & 4.0 & 6.0 & 10.59 & 2.12 & 3.2 & 4.26 \\
\hline
\end{tabular}

flows and annual river discharge to the ocean in recent years. Firgures 4 and 5 shows the average monthly river discharge and the temporal variation objectives in the Luanhe and Haihe estuaries, respectively.

It is indicated that the annual freshwater inflow is sufficient for fulfilling the requirements of the ecological objectives for the Luanhe Estuary since the monthly river discharge is consistent with the ecological objectives in $1950 \sim 1960$ s (Figure 4a). However, the average monthly river discharge in 1980 s tends to distribute uniformly due to the influence of reservoirs and irrigations (Figure 4b). Table 6 indicates that the runoffs from the Haihe and the Zhangweixin Rivers could not fulfill the minimum requirements of the ecosystems in recent years even if the impacts of pollutant loadings were not 
considered. As shown in Figure 5, the ratio of the discharge in August to the annual river discharge is $55.95 \%$ for the Haihe estuary in $1980 \mathrm{~s}$, which is much higher than that of the ecological objectives (39.9\%). This is due to the fact that the floodwater must be sluiced during flood seasons. The ratio of the discharge in the Zhangweixin estuary in August to the yearly total is $60.75 \%$ in 1996 ; while no discharge occurred before July. Furthermore, the annual river discharge focused on July in 1992 and 1993, where the primary characteristics of the estuaries have disappeared. As the temporal variation of the natural river discharge is closely related to the relevant river ecological conditions, it is critical that the annual water requirement at different levels with reasonable temporal variations be fulfilled in order to meet the basic requirement of estuarine ecosystems.

Table 6. Annual River Discharges and Environmental Flows for the Estuaries in the Haihe River Basin $\left(10^{8} \mathrm{~m}^{3}\right)$

\begin{tabular}{|c|c|c|c|}
\hline Estuary & Haihe Estuary & $\begin{array}{l}\text { Luanhe } \\
\text { Estuary }\end{array}$ & $\begin{array}{c}\text { Zhangweixin } \\
\text { Estuary }\end{array}$ \\
\hline $\begin{array}{l}\text { Annual discharge } \\
(1950 \sim 1969)\end{array}$ & $\begin{array}{c}49.85 \\
(1956 \sim 1969)\end{array}$ & 44.23 & $\begin{array}{c}10.87 \\
(1955 \sim 1969)\end{array}$ \\
\hline $\begin{array}{l}\text { Annual discharge } \\
(1980 \sim 1998)\end{array}$ & 2.36 & 14.31 & 1.11 \\
\hline Maximum & 7.49 & 12.61 & 5.77 \\
\hline Medium & 5.54 & 7.50 & 4.48 \\
\hline Minimum & 4.24 & 5.06 & 3.22 \\
\hline
\end{tabular}

\subsection{Different Functions of Environmental Flows}

Figure 6 shows the environmental flows for the water cycle at different levels. It is indicated that there are no distinct differences between the water requirements of the water cycle in different estuaries since the climate conditions in these estuaries of Haihe river basin are similar. Water requirements for the habitat in estuary are related to many factors. This generally leads to variations of environmental flows in the same basin or in the neighboring areas (shown in Figure 7).

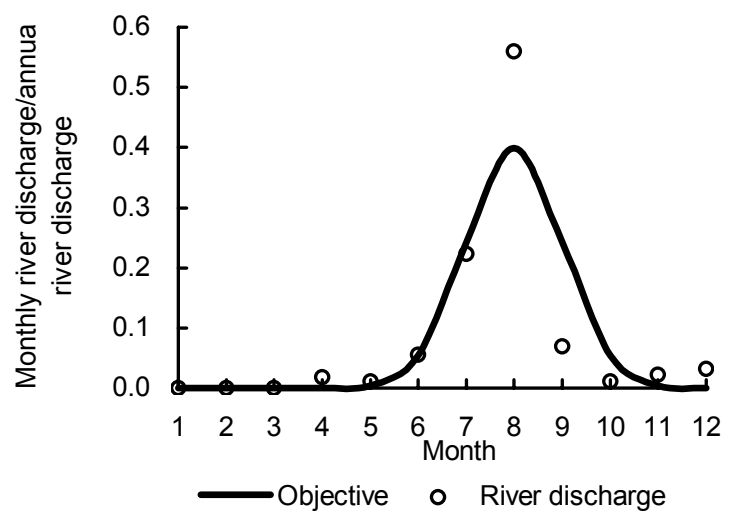

Figure 5. The monthly river discharge in the Haihe estuary in 1980 s and the temporal variation objectives.

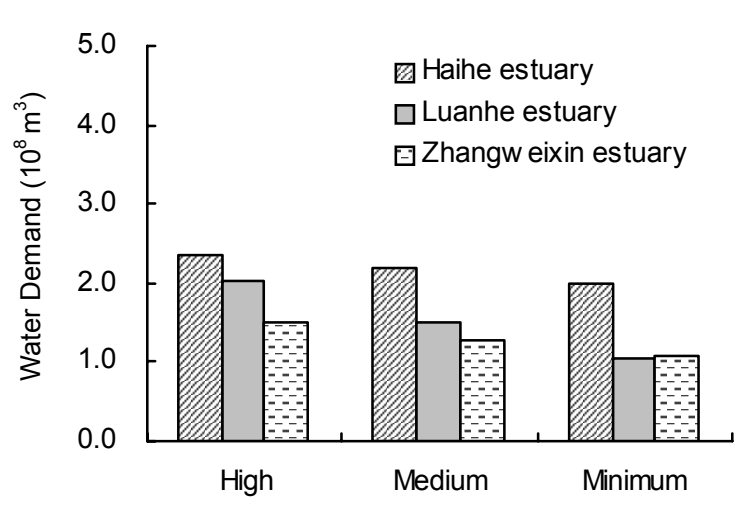

Figure 6. Water requirements for water cycles in different estuaries.

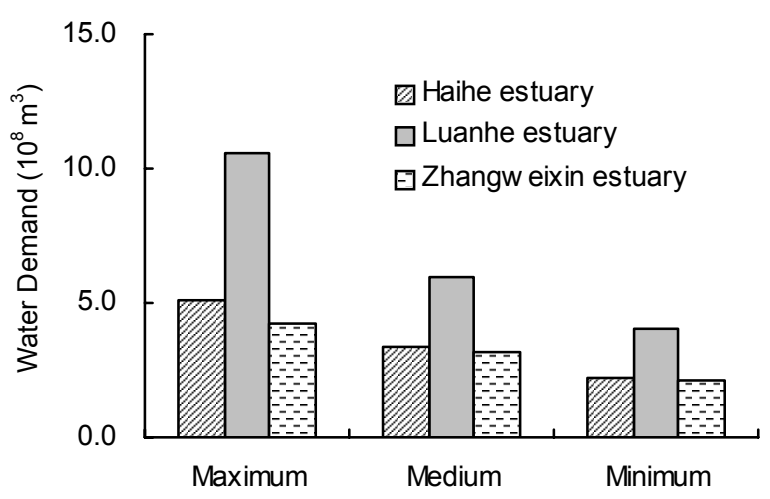

Figure 7. Water requirements for wildlife habitats in different estuaries.

Water requirements for the biological cycle are less than those for other processes although the spatial variation of water requirements for such a process is more complicated due to effects of water quantity/quality in habitat and human activities. Therefore, to effectively preserve or restore the estuarine ecosystem, fulfillment of the water demands for the water cycle and the habitat should be given higher priorities. Environmental flows should also be emphasized for estuaries where high-level aridty and average annual river discharge exist. The temporal variation of the natural flow is generally correlated to the seasonal rainfall. Consequently, the monthly variations of environmental flows will be more apparent in estuaries where difference between the average rainfall of flood season and that of the dry season is significant.

Figure 8 shows the ratio of the different types of environmental flows to the total water requirements at different levels. It is indicated that the ratio of water requirements for the water cycle to the total is about $35 \%$ under minimum levels of ecological objectives (to fulfill the basic requirements of esturarine ecosystems). The ratio for the water requirement of salinity balance is around $62 \%$. These items occupy most of the environmental flows. As the ecological objectives become stricter, the ratio of the water requirements for the water cycle 
decreases gradually; and the ratio of the water requirements for the sediment transport increases distinctly. The sediment transport is influenced directly by the reduction of the river discharge, and so is the balance of salinity.

The ratio of water requirements for salinity ranges from 65 to $70 \%$ at different levels. This implies that the water requirement of keeping salinity balance is always a main contributor to the total environmental flows. Meeting the water requirement for evaporation and maintaining a reasonable salinity in the estuaries should be the primary concerns for calculating the environmental flows.

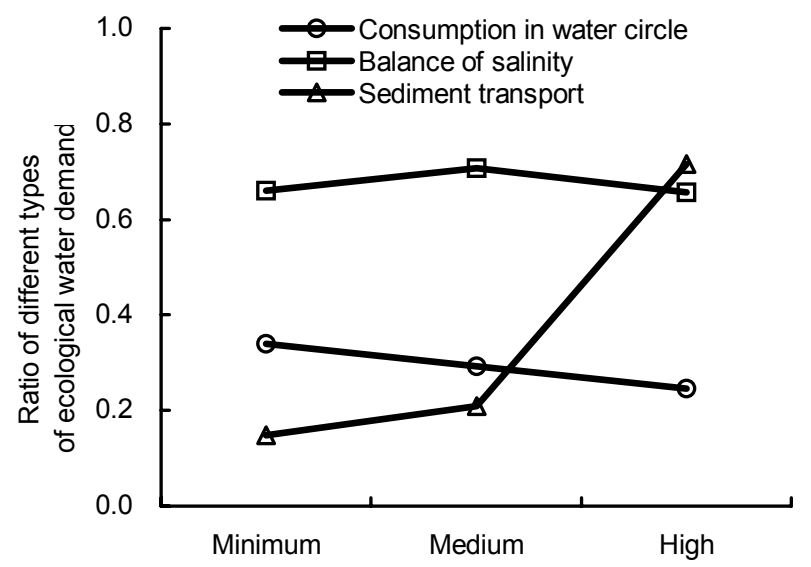

Figure 8. Ratio of different types of environmental flows in the estuaries of the Haihe River Basin at different levels.

\section{Conclusions}

1) This paper investigated the characteristics of environmental flows in estuaries and developed a new method for calculating environmental flows considering different esturine functions. Three estuaries in the Haihe River Basin in China were presented as case studies for verifying the applicability and practicability of the proposed method.

2) The results indicated that the minimum annual environmental flow requirements for the Haihe, Luanhe and the Zhangweixin Estuaries were $5.97 \times 10^{8}, 6.80 \times 10^{8}$ and $4.96 \times 10^{8} \mathrm{~m}^{3}$ respectively. For the Luanhe Estuary, the annual freshwater inflow was sufficient for meeting the requirements of the ecological objectives. Moreover, the average monthly river discharge in 1980s tended to distribute uniformly due to the influence of reservoirs and irrigations.

3) Runoff from the Haihe and the Zhangweixin Rivers could not fulfill the minimum water requirements in recent years. The differences between the monthly river discharge and the water requirements for the ecological objectives were significant. It is critical that the annual water requirement at different levels with reasonable temporal variations be fulfilled in order to meet the basic requirement of estuarine ecosystems.

4) To effectively preserve or restore the estuarine ecosys- tem, fulfillment of the water demands for the water cycle and the habitat should be given higher priorities. Generally, the water requirements for keeping reasonable salinity balance can fulfill the water requirements for sediment transport.

5) Sediment transport was influenced directly by the reduction of the river discharge, and so was the balance of salinity.

Acknowledgments. This work was supported by the Natural Science Foundation of China (Grand No. 50239020) and the State Major Basic Project Program (2002CB412400).

\section{References}

Adams, J.B. and Bate, G. C. (1994). The fresh water requirements of estuarine plants incorporating the development of an estuarine decision support system. Volume 1. South African Water Research Commission. WRC Report 292/1/94 ISBN186845 1305.

Benetti, A.D., Lanna, A.E. and Cobaichini, M.S. (2004). Current practices for establishing environmental flows in Brazil. River Res. Appl., 20, 427-444.

Doering, P.H., Chamberlain, R.H. and Hauner, D.E. (1998). Using submerged aquatic vegetation to establish minimum and maximum freshwater inflow to the Caloosahatchie Estuary, Florida. Estuaries, 25, 1343-1354.

Cui, B.S. and Yang, Z.F. (2002). Water consumption for eco-environmental aspect on wetlands. ACTA Scientiae Circumstantiae, 22(2), 219-224 (in Chinese).

Flannery, M.S., Peebles, E.B. and Montgomery, R.T. (2002). A percent-of-flow approach for managing reductions of freshwater inflows from unimpounded rivers to the southwest Florida Estuaries. Estuaries, 25, 1318-1332.

Gipple, C.J. and Stewardson, M.J. (1998). Use of wetted perimeter parimeter in defining minimum environmental flows. Regul. Rivers: Res. Manage., 14, 53-67.

King, J. and Louw, D. (1998). Instream flow assessments for regulated rivers in South Africa using the Building Block Methodology. Aquatic Ecosyst. Health manage., 1(2), 109-124

Jowett, I.G. (1997). Instream flow methods: A comparison of approaches. Regul. Rivers: Res. Manage., 13, 115-127.

Li, L.J. and Zhen, H.X. (2000). Environmental and ecological water consumption of river systems in Haihe-Luanhe Basins. ACTA Geographica Sinica, 55(4), 496-500 (in Chinese).

Liu, J.L. and Yang, Z.F. (2002). Study on the ecological and environmental water demand of lakes in the Haihe-Luanhe Basin North China. J. Environ. Sci., 22(2), 220-229 (in Chinese).

Peirson, W.L., Bishop, K. and Van Senden, D. (2002). Environmental Water Requirements to Maintain Estuarine Processes, WRL Technical Report Number 3, ISBN 06425 48277, School of Civil and Environmental Engineering, University of New South Wales, Environment Australia.

Matsumoto, J., Powell, G. and Brock, D. (1994). Freshwater-inflow need of estuary computed by Texas estuarine MP model. J. Water Resour. Plan. Manage., 120, 693-714.

Tharme, R.E. (2003). A global perspective on environmental flow assessment emerging trends in the development and application of environmental flow methodologies for rivers. River Res. Appl., 19, 397-441.

Yang, Z.F. and Zhang, Y. (2003). Comparison of methods for ecological and environmental flow in river channels. J. hydrodyn. Ser. A., 18(3), 294-301 (in Chinese).

Yang, Z.F., Cui, B.S. and Liu, J.L. (2003). Theory, Methods and the Application of Eco-environmental Water Demands, Science Press Science Press, Beijing (in Chinese). 